\title{
Über die Bestimmung des Schwefels in unorganischen Sulfiden durch Glühen derselben in einem Sauerstoffstrome und Auffangen der flüchtigen Oxyde in Wasserstoff- superoxyd.
}

\author{
Von \\ P. J ANNASCH und H. LeHNERT.
}

V. Abhandlung:

Die genauen und rasch zu erzielenden Resultate, welche schon früher nach dieser Methode erhalten wurden, ${ }^{1}$ veranlafsten uns zur weiteren Ausdehnung derselben auf das Quecksilbersulfid und das Zinnsulfür. Die von uns neuerdings benutzte Vorrichtung ${ }^{2}$ besteht aus einem mit Sauerstoff gefüllten Gasometer nebst Trockenflasche und Natronkalkrohr, dem sich der Verbrennungsapparat anschliefst in Verbindung mit den Absorptionsgefälsen, bestehend aus einer zweifach tubulierten Kugelvorlage, zwei Póligotröhren und am Schlufs einem grolsen Erlenmeyerkolben. Die Füllung der letzteren besteht aus 3-4\% igem Wasserstoffsuperoxyd. Mufs man in Ermangelung desselben Bromwasser benutzen, so vergesse man nicht, den betreffenden Vorlagen eine kleine Extra-Brommenge hinzuzutröpfeln, den Endbecherglaskolben aber mit Natronlauge oder Alkohol zur Verschluckung der Brom- und Bromwasserstoffsäure-Dämpfe zu beschicken.

\section{Natürlicher Zinnober.}

Man nehme zur Analyse $0.5-0.75 \mathrm{~g}$ zerriebenes Material und bediene sich zur Erhitzung der Substanz eines Flachbrenners (als Aufsatz für die gewöhnlichen Gasbrenner). Der Zinnober verbrennt und destilliert unter blauer Flammenerscheinung und Erglühen

1 Vergl. die Analysen von Pyrit, Zinkblende, Kupferkies, Antimonit, Realgar, Auripigment und Molybdänglanz Journ. pr. Chem. 40, 237; 41, 566; 45, 94.

2 Diese Zeitschr. 6, 303 und 9, 194. 
äufserst leicht über, derngemäls man die anzuwendende Hitze zu regulieren hat. Zum Weitertreiben der Zersetzungsprodukte verwendet man gleichzeitig eine $2-3 \mathrm{~cm}$ hohe Gasflamme. Geht nach Verlauf von 20-30 Minuten Glühdauer nichts mehr über und hat man mit beweglicher Flamme alles im Knierohre und der Einschliffpartie des Apparates haften gebliebene Quecksilber verjagt, so lälst man allmählich im verlangsamten Gasstrome erkalten und sammelt die Vorlageflüssigkeiten in einer grolsen flachen Porzellanschale. Das das sublimierte metallische Quecksilber enthaltende Kugelrohr muls besonders mit heifser Salpetersäure ausgespritzt werden, wodurch sich das Metall leicht und vollständig vom Glase loslöst. Man verdampft jetzt die gesamte Flüssigkeit auf ein sehr kleines Volumen, setzt Königswasser und rote rauchende Salpetersäure hinzu, um etwa noch nicht gelöstes Quecksilber dadurch rasch in Lösung zu bringen und trocknet nun vollständig ein zur gründlichen Beseitigung der die spätere Reinfällıng des Quecksilbers störenden Salpetersäure, worauf die Wiederaufnahme in Wasser $(75-90 \mathrm{ccm})$ und verdünnter Salzsäure $(10 \mathrm{ccm})$, die Fällung der vorhandenen Schwefelsäure, womöglich mit einer berechneten Menge von Chlorbaryum, die spätere Entfernung des zugesetzten Überschusses an letzterem und die schliefsliche Ausfällung und Wägung des Quecksilbers als Sulfid unter den bekannten Bedingungen erfolgt. Es empfiehlt sich, das Verbindungsrohr vor der Einfüllung des Zinnoberpulvers leer zu wägen, um nachträglich kleine Mengen von beigemischtem Quarz durch direkte Wägung des Rückstandes bestimmen zu können. War gleichzeitig Eisen vorhanden, so wird der restierende, nichtflüchtige Teil des Minerals nach vorherigem Erwärmen mit starker Salzsäure in eine Porzellanschale gebracht und wie üblich weiter behandelt.

Ist ein natürlicher oder künstlicher Zinnober reichlich mit Kieselsäure, Eisen, Kohle etc. verunreinigt, so bietet die Verbrennungsmethode entschiedene Vorteile gegenüber jedem Lösungsverfahren. Wir erhielten mitunter kohlehaltige Zinnobersorten, deren Lösungen in Königswasser, Brom u. s. f. niemals klar filtrierten, resp. die Filter hierbei vollständig verstopften, so dafs ihre Analyse lästige Schwierigkeiten verursachte, welche bei Anwendung der Sauerstoffmethode vollkommen in Wegfali kamen. Der vorhandene Kohlenstoff kann in einer besonderen Portion durch Glühen im Sauerstoffstrome und Absorption der gebildeten Kohlensäure in Kalilauge gewichtsanalytisch bestimmt werden. Man benutzt hierzu 
das gleiche Verbrennungsrohr und schaltet jetzt an Stelle der Vorlagen zwei besondere Röhren ein, die eine (U-förmig) mit Glaswolle gefüllt zur Aufnahme des überdestillierten Quecksilbers und die andere (horizontal) mit Bleisuperoxyd-Bleioxyd-Glaswolle beschickt zum Zurückhalten der gleichzeitig gebildeten schwefligen und Schwefelsäure.

Zinnober-Analyse:

$0.5070 \mathrm{~g}$ Zinnober gaben $=0.5500 \mathrm{BaSO}_{4}=0.0759 \mathrm{~S}=14.97 \%$ Schwefel und $0.4998 \mathrm{HgS}=0.4308 \mathrm{Hg}=84.87 \%$ Quecksilber. $99.84 \%$

\section{Analyse von käuflichem, krystallisiertem Zinnsulfür. ${ }^{1}$}

Die in den Apparat entweder direkt eingewogene oder sauber aus einem Wägeröhrchen eingefüllte, gut verriebene Substanz verbrennt ebenfalls leicht unter lebhaften Erglühungserscheinungen. Man erhitzt so lange, bis das zurückbleibende Zinndioxyd keinerlei Veränderung mehr zeigt. Zum Schlufs wird etwas kräftiger geglüht, aber nicht etwa bis zur Erweichung des Glases. Die gebildete Zinnsäure kann direkt im Apparat gewogen werden. Eine Probe davon im Platinschälchen oder -Löffel mit Soda und Salpeter geschmolzen u. s. f. darf keine Reaktion auf Schwefelsäure mehr liefern.

In Blättern krystallisiertes Zinnsulfür:

I. Analyse: $0.5023 \mathrm{~g}$ Zinnsulfür gaben:

$0.5012 \mathrm{SnO}_{2}=0.3942 \mathrm{Sn}=78.50 \% \mathrm{Sn}$ und

$0.7842 \mathrm{BaSO}_{4}=0.1008 \mathrm{~S}=20.07 \% \mathrm{~S}$.

$98.57 \%$

II. Analyse: $0.6374 \mathrm{~g}$ Zinnsulfür gaben:

$0.6374 \mathrm{SnO}_{2}=0.5015 \mathrm{Sn}=78.52 \% \mathrm{Sn}$ und

$0.8884 \mathrm{BaSO}_{4}=0.1279 \mathrm{~S}=20.06 \% \mathrm{Sn}$.

$98.58 \%{ }^{2}$

Wir beschäftigen uns gegenwärtig mit der Analyse des Goldschwefels, des Zinnkieses, des Proustits und Kobaltglanzes in Verbindung mit der Salzsäurestrommethode ${ }^{3}$ und anderer wichtiger Sulfide,

${ }^{1}$ Dasselbe stellte braunschwarze metallisch glänzende Blätter dar.

2 Der Rest bestand aus zufälligen Beimengungen von $\mathrm{H}_{2} \mathrm{O}, \mathrm{Cl}, \mathrm{O}(\mathrm{Oxy}$ sulfid) und Alkali.

${ }^{3}$ A. a. 0 .

Bei der Redaktion eingegangen am 27. Februar 1896. 